\title{
Esophageal leaks: I thought that glue was not effective
}

\section{다)(1) $(-)$}

\author{
Authors \\ Ignacio Fernández-Urién, Juan Vila \\ Institution \\ Complejo Hospitalario de Navarra - Gastroenterology, \\ Pamplona, Navarra, Spain \\ Bibliography \\ DOI https://doi.org/10.1055/a-0599-6288 | \\ Endoscopy International Open 2018; 06: E1100-E1102 \\ (c) Georg Thieme Verlag KG Stuttgart · New York \\ ISSN 2364-3722
}

Unfortunately, esophageal perforations, fistulas and leaks are not "infrequent" conditions. As pointed by Goenka et al. [1] in a recent review article, perforation, fistula and leak are terms that are often used interchangeably but, in strict terms, they are completely different. Perforation is defined as an acute full thickness defect; leak is defined as a disruption of a surgical anastomosis resulting in a fluid collection; and fistula is defined as an abnormal communication between two epithelialized surfaces.

In this issue of Endoscopy International Open, Ojima et al. [2] publish an original article evaluating the efficacy and safety of endoscopic injections of alpha-cyanoacrylate monomer in 25 patients with intractable esophageal "fistulas" secondary to esophageal surgery. This study, although interesting and necessary, incorrectly uses the term fistula instead of leak and, indeed, patients with esophagotracheal fistulas were excluded from the study. This has important significance in terms of efficacy and safety.

It is well-known that leaks are usually the step prior to fistula development and that they usually close better and earlier. On the other hand, endoscopic injection of tissue sealants is probably safer in leaks than in fistulas. In the leak scenario, the glue excess would usually reach a cavity while in the fistula scenario, it would reach the airway, leading to respiratory or pulmonary complications. Management of leaks and fistulas is quite similar but not equal in terms of timing, techniques, follow-up and outcomes. Therefore, the results of Ojima et al. [2] should be taken into account only in patients with esophageal leaks and not those with fistulas.

The prevalence of gastrointestinal leaks has increased in recent years, probably due to the increasing complexity of both surgery and endoscopic interventions. In fact, they are usually secondary to esophagogastric surgery. In a recent multicenter registry that included 2704 esophagectomies, anastomotic leaks occurred in $11.4 \%$ of cases [3] but prevalence has been reported to be up to $50 \%$ [4]. Because esophageal leaks are associated with high morbidity and mortality rates - up to $80 \%$ if an esophago-respiratory fistula develops - they should be considered potentially life-threatening events and treatment should be immediate to avoid severe consequences such as mediastinitis, pneumonia and other fatal events $[5,6]$. In fact, in a recent study, early stent insertion was identified as a significant independent predictor of successful sealing and thus, morbidity reduction [7].

Treatment of anastomotic leak remains controversial, as the indications for surgical, conservative and endoscopic therapy remain non-standardized. Several options have been reported to treat esophageal leaks. On the one hand, the classic therapy is surgery. Surgical techniques and timing depend mainly on lesion nature, size, location, previous interventions and patient clinical status and normally include repair, esophagectomy or cervical exclusion together with drainage of mediastinal and peritoneal contamination if present. However, despite continuous surgical advances, the mortality rate for re-intervention is still high [8]. The main reason for the "poor numbers" for surgery in this scenario is that most patients who undergo reintervention are in very poor physical and nutritional condition due to concomitant infections as well as absence of oral feeding. Thus, surgery should be considered as the last treatment step and reserved to those refractory cases.

Conceptually, the endoscopic approach is faster, less invasive and can be easily repeated in case of non-response. In recent years, development of new endoscopic devices, concepts and techniques has led to new therapeutic options, resulting in several published reports of successful interventions in this clinical scenario. Current endoscopic techniques for esophageal leaks include self-expandable stents, usually as the firstline option (metallic, plastic and biodegradable) and clips 
(both through-the-scope and over-the-scope clips), suturing devices, tissue sealants and endoscopic vacuum therapy as second-line alternatives [1,9-16]. Surprisingly, all of them, used alone or combined, have been demonstrated to be "almost perfect" since $80 \%$ to $90 \%$ of leaks were successfully repaired. However, these cases have been published as case reports or in small series. So, to date, the quality of evidence is very low and does not allow for following/giving any strong recommendation. On the other hand, endoscopists have the perception that literature "numbers" in these setting do not reflect outcomes in daily practice. Therefore, larger series of endoscopic therapy for esophageal leaks are welcome to give us "light in darkness."

Ojima et al. [2] report complete closure of leaks in 22 of 25 patients, which means a success rate of $88 \%$ with no complications and/or recurrence. The authors conclude that these results suggest that alpha-cyanoacrylate injection could be a good therapeutic option in these patients. Moreover, alpha-cyanoacrylate monomer may work even better than the classic nbutyl 2-cyanoacrylate or 2-octyl cyanoacrylate polymers due to some advantages such as its stronger adhesive and antibacterial properties. Finally, the authors comment that a large multicenter, randomized, double-blind, placebo-controlled phase III clinical trial is planned to prove the clinical application of their proposal.

To our knowledge, this is one of the largest series of endoscopic therapy of esophageal leaks, and no doubt, using cyanoacrylate. The complete leak closure rate reported by Ojima et al. [2], although excellent, is somewhat optimistic because they considered both leak reduction and complete closure as successful treatments. On the other hand, there are no data regarding patient clinical outcome in terms of symptom relief and proper long-term follow-up. So, the authors should have concluded that endoscopic injection of alpha-cyanoacrylate monomer is effective in the short term in reducing/closing esophageal leaks after surgery. Anyway, these numbers together with those of similar studies $[1,12,13]$ are good enough to consider endoscopic cyanoacrylate injection as a valid therapeutic alternative in this clinical scenario. Advantages of cyanoacrylate injection are costs, safety profile and the possibility of using it in combination with other techniques while the disadvantages are the number of sessions needed - up to 14 in the study of Ojima et al. [2] - and poor outcomes in leaks greater than $10 \mathrm{~mm}$.

So, what therapy should we choose? Because there are no comparative studies between the different endoscopic alternatives, it is difficult to establish a therapeutic algorithm in these patients. Determining the optimal therapy for such patients requires: 1) careful examination of patient clinical status; 2) intensive examination of the anastomotic defect by means of chest computed tomography, $x$-ray barium/gastrografin study and upper endoscopy; and 3) a review of all available options, local expertise and previous experience. It is important to remember that the approach to esophageal leaks should always be individualized and multidisciplinary.

Based on literature data and as a general rule, fully/partially covered self-expandable metallic stents (SEMS) should be the first-line option for esophageal leaks except in patients who have poor-response predictors, such as failure at first attempt, fistula development, leak greater than $20 \mathrm{~mm}$ and/or poor clinical status as demonstrated by two recent papers $[17,18]$. Due to the high migration rate for stents - up to $26 \%$ [19] - use of anchoring systems such as clips or suturing devices are highly recommended to keep the stents "on site" closing the defect as much as needed. Usually, 4 to 8 weeks should be enough. In situations in which SEMS are likely to fail $[17,18]$, the "other" endoscopic alternatives should be taken into account, those being tissue sealants and endoscopic vacuum therapy, the most promising options.

\section{Competing interests}

None

\section{References}

[1] Goenka MK, Goenka U. Endotherapy of leaks and fistula. World J Gastrointest Endosc 2015; 7: $702-713$

[2] Ojima T, Nakamura M, Nakamori M et al. Endoscopic treatment of esophageal fistulas after esophagectomy with injection of an alphacyanoacrylate monomer: a phase II study. Endosc Int Open 2018; 06: E1093-E1099

[3] Low DE, Kuppusamy MK, Alderson D et al. Benchmarking Complications Associated with Esophagectomy. Ann Surg 2017: doi:10.1097| SLA.0000000000002611

[4] Lerut T, Coosemans W, Decker G et al. Anastomotic complications after esophagectomy. Dig Surg 2002; 19: 92 - 98

[5] Alanezi K, Urschel JD. Mortality secondary to esophageal anastomotic leak. Ann Thorac Cardiovasc Surg 2004; 10: 71 - 75

[6] Rutegard M, Lagergren P, Rouvelas I et al. Intrathoracic anastomotic leakage and mortality after esophageal cancer resection: a population-based study. Ann Surg Oncol 2012; 19: 99-103

[7] Huh CW, Kim JS, Choi HH et al. Treatment of benign perforations and leaks of the esophagus: factors associated with success after stent placement. Surg Endosc 2018: doi:10.1007/s00464-018-6096-1

[8] Griffin SM, Lamb PJ, Dresner SM et al. Diagnosis and management of a mediastinal leak following radical oesophagectomy. Br J Surg 2001; 88: $1346-1351$

[9] Dasari BV, Neely D, Kennedy A et al. The role of esophageal stents in the management of esophageal anastomotic leaks and benign esophageal perforations. Ann Surg 2014; 259: 852-860

[10] Lee HL, Cho JY, Cho JH et al. Efficacy of the over-the-scope clip system for treatment of gastrointestinal fistulas, leaks, and perforations: a Korean multi-center study. Clin Endosc 2018; 51: 61-65

[11] Ngamruengphong S, Sharaiha RZ, Sethi A et al. Endoscopic suturing for the prevention of stent migration in benign upper gastrointestinal conditions: a comparative multicenter study. Endoscopy 2016; 48: 802

[12] Kotzampassi K, Eleftheriadis E. Tissue sealants in endoscopic applications for anastomotic leakage during a 25 -year period. Surgery 2015; 157: $79-86$

[13] Ojima T, Nakamori M, Nakamura M et al. Successful treatment of esophageal fistulas with endoscopic injection of alpha-cyanoacrylate monomer. Endoscopy 2014; 46: E62-E63

[14] Kuehn F, Loske G, Schiffmann L et al. Endoscopic vacuum therapy for various defects of the upper gastrointestinal tract. Surg Endosc 2017; 31: $3449-3458$ 
[15] Valli PV, Mertens JC, Kröger A et al. Stent-over-sponge (SOS): a novel technique complementing endosponge therapy for foregut leaks and perforations. Endoscopy 2018; 50: 148-153

[16] Di Leo M, Maselli R, Ferrara EC et al. Endoscopic Management of Benign Esophageal Ruptures and Leaks. Curr Treat Options Gastroenterol 2017; 15: 268-284

[17] Persson S, Rouvelas I, Kumagai K et al. Treatment of esophageal anastomotic leakage with self-expanding metal stents: analysis of risk factors for treatment failure. Endosc Int Open 2016; 4: E420 - E426
[18] van Halsema EE, Kappelle WFW, Weusten BLAM et al. Stent placement for benign esophageal leaks, perforations, and fistulae: a clinical prediction rule for successful leakage control. Endoscopy 2018; 50: $98-108$

[19] van Boeckel PG, Sijbring A, Vleggaar FP et al. Systematic review: temporary stent placement for benign rupture or anastomotic leak of the oesophagus. Aliment Pharmacol Ther 2011; 33: 1292 - 1301 